\title{
Local Cerebral Blood Flow in the Newborn Rabbit: An Autoradiographic Study of Changes during Development
}

\author{
U. I. TUOR \\ Division of Neonatologv, Hospital for Sick Children, 555 University Avenue, \\ Toronto, Ontario, M5G $1 \times 8$, Canada
}

\begin{abstract}
Cerebral ischemia in the neonate is an important cause of hypoxic-ischemic encephalopathy. Thus, it is important to have an economical and readily available animal model in which to study the local control of the cerebral circulation in the perinatal period. This study demonstrates that the newborn rabbit, a rather immature species at birth, is a suitable neonatal model in which to measure local cerebral blood flow with quantitative iodo $\left[{ }^{14} \mathrm{C}\right.$ antipyrine autoradiography. One or $2 \mathrm{~d}$ after birth, local cerebral blood flow in the newborn rabbit is low, but flow varies distinctly between regions $[$ e.g. $8.9 \pm 1.5 \mathrm{~mL}$. $\mathrm{kg}^{-1} \cdot \mathrm{s}^{-1}\left(53 \mathrm{~mL} \cdot 100 \mathrm{~g}^{-1} \cdot \mathrm{min}^{-1}\right)$ in the nucleus tractus solitarius and $3.4 \pm 0.7 \mathrm{~mL} \cdot \mathrm{kg}^{-1} \cdot \mathrm{s}^{-1}\left(20 \mathrm{~mL} \cdot 100 \mathrm{~g}^{-1}\right.$. $\left.\mathrm{min}^{-1}\right)$ in the frontal cortex]. During early postnatal development (i.e between 1 and $8 \mathrm{~d}$ ), local cerebral blood flow does not change greatly. However, by $17 \mathrm{~d}, 22$ of 26 brain regions exhibit significant marked increases (200-350\%) in local cerebral blood flow when compared with blood flow in the newborn. Between 17 and $40 \mathrm{~d}$ postnatally, cerebral blood flow continues to increase in 16 of 26 regions (e.g. thalamic areas). In four of the cerebral cortical areas, elevations in flow continue during the period between $\mathbf{4 0} \mathrm{d}$ of age and adulthood. In contrast to the generalized increases in flow occurring postnatally, a few brain regions (i.e. within the pons and medulla) exhibit only minor changes in cerebral blood flow. The differential pattern and lower basal levels of cerebral blood flow in the neonate compared with the adult may be important determinants in regional susceptibility of the brain to ischemia. (Pediatr Res 29: 517-523, 1991)
\end{abstract}

Adequate blood flow to the brain is crucial for its survival, and an insufficiency of cerebral blood flow, as is associated with hypoxic-ischemic encephalopathy, is a common cause of neurologic problems in the human infant. Clearly, understanding the control of the local cerebral circulation in the perinatal period under normal and pathophysiologic conditions is important for determining appropriate management and treatment strategies. This requires an animal model in which the local requirements and regulatory responses of the brain during development can be investigated readily.

Animal species that are suitable for the study of the local regulation of perinatal cerebral blood flow are limited in number. In the past, developmental and pathophysiologic changes in

Received August 22, 1990; accepted December 14, 1990.

Correspondence and reprint requrests: Dr. U. Tuor, Division of Neonatology, Hospital for Sick Children, 555 University Avenue, Toronto, Ontario, M5G IX8, Canada.

Supported by a grant from the Heart and Stroke Foundation of Ontario and a scholarship from the Hospital for Sick Children Foundation. cerebral blood flow have been measured with quantitative autoradiographic techniques in the newborn $\operatorname{dog}(1-4)$. However, this species is rather expensive. The newborn rat, although economical, is so small at birth that it is not possible to catheterize vessels or obtain blood samples necessary to monitor physiologic changes that may influence the cerebral circulation. Nevertheless, techniques for autoradiographic cerebral blood flow measurements have been adapted for rats 7 or $10 \mathrm{~d}$ of age $(5,6)$. The newborn lamb and piglet are of an appropriate size for frequent sampling of blood and recording of various physiologic parameters; however, these animals are rather large for extensive autoradiographic studies of cerebral blood flow. Instead, repeated measures of cerebral blood flow in rather gross brain regions are often made with microspheres in these species.

The newborn rabbit is economical, readily available, and of a size suitable for monitoring the physiologic variables important in the local control of the cerebral circulation. This study is, to the author's knowledge, the first report in which local cerebral blood flow was measured in newborn rabbits with quantitative autoradiographic techniques. The results demonstrate that brain blood flow in the newborn rabbit is low in most regions, but that there are well-defined differences in the local levels of blood flow between regions. In addition, there are marked heterogeneous increases in blood flow postnatally.

\section{MATERIALS AND METHODS}

Animal preparation. Pregnant female rabbits (New Zealand White) were housed $1 \mathrm{wk}$ before delivery in the animal facility and, after birth, the infant rabbits were kept with their mother until the day of the experiment $(1,2,8,17$, or $40 \mathrm{~d}$ of age). The young rabbits were anesthetized with halothane during which period a vein was catheterized (Silastic medical tubing, 0.0030 $\mathrm{m}$ inner diameter, Dow Corning, Midland, MI). Anesthesia was subsequently maintained with urethane ( $1.5 \mathrm{mg} / \mathrm{kg}$ i.v. $)$. Adult rabbits were anesthetized with urethane injected into an ear vein. In all animals, a tracheostomy was performed and a tube placed in the trachea. Catheters (PE50 tubing, tapered) were placed in the femoral arteries to measure arterial blood pressure and sample arterial blood. One microsample $(80-300 \mu \mathrm{L})$ of arterial blood was analyzed for $\mathrm{PCO}_{2}, \mathrm{PO}_{2}$, and $\mathrm{pH}$ before the measurement of cerebral blood flow. Body temperature was monitored and controlled with a heating lamp $\left(38-39^{\circ} \mathrm{C}\right)$. These experiments were approved by the Animal Care Committee of the Hospital for Sick Children.

Measurement of local cerebral blood flow. Local cerebral blood flow was measured with iodo $\left[{ }^{14} \mathrm{C}\right] \mathrm{antipyrine}$ quantitative autoradiography using procedures similar to those originally developed for the rat (7) and as used previously in this laboratory (8). In young rabbits, the radioactive tracer iodo $\left[{ }^{14} \mathrm{C}\right]$ antipyrine $(\sim 5.5$ $\mathrm{MBq} / \mathrm{kg}$ in $0.5-1 \mathrm{~mL}$ saline; American Radiolabelled Chemicals, St. Louis, MO) was infused over $30 \mathrm{~s}$ at an increasing rate of 
infusion, thereby producing an increasing arterial concentration of tracer. During the infusion, six to 12 timed arterial samples $(\sim 30 \mu \mathrm{L}$ each) were collected into heparinized tubes from a freely flowing arterial catheter. At $30 \mathrm{~s}$, the animal was killed by the infusion of an overdose of sodium pentobarbital and by decapitation. The brain was removed within 2 min, immediately frozen in isopentane $\left(-35^{\circ} \mathrm{C}\right)$, and coated with a chilled embedding medium (Lipshaw, Detroit, MI). Aliquots $(20 \mu \mathrm{L})$ of the arterial blood samples were pipetted into water $(0.5 \mathrm{~mL})$, hemolyzed with Scintigest ( $30 \mu \mathrm{L}$; Fisher Scientific, Fair Lawn, NJ), bleached with $30 \% \mathrm{H}_{2} \mathrm{O}_{2}(30 \mu \mathrm{L})$, and prepared for scintillation counting (LS8000; Beckman, Irvine, CA) by adding scintillant (Aquasol; New England Nuclear, Boston, MA). In adult rabbits, the procedures were similar; however, we were able to economize on tracer because cerebral blood flow in adults is greater than that in newborns and thus less tracer was required to achieve equivalent concentrations in brain $(\sim 2 \mathrm{MBq} / \mathrm{kg})$. In addition, in the adult animals, arterial samples were collected from a catheter placed in the brachial artery - an artery considered to carry blood representative of that in the cerebral arteries.

Brain sections (20- $\mu \mathrm{m}$ thick) were cut semiserially in a cryostat at $-22^{\circ} \mathrm{C}$, mounted on coverslips, and dried at $60^{\circ} \mathrm{C}$. Additional sections were mounted on slides for staining with Luxol fast blue and cresyl violet or hematoxylin and eosin. Autoradiograms were prepared by applying x-ray film (OMC1, Kodak, Rochester, NY) to the sections in a light-tight cassette for 7-28 d. A series of 16 calibrated standards $(0.4-50 \mathrm{MBq} / \mathrm{g})$ were also exposed to the film. Gray levels and tissue concentrations of tracer were measured with a computer-based image analysis system (MCID; Imaging Research Inc., St. Catherine's, Ontario, Canada). For each region of interest, cerebral blood flow was computed using a partition coefficient of 0.6 (measured as described below) and a correction for catheter lag. Mean cerebral blood flow for each cerebral region was determined from an average of at least six bilateral measurements of blood flow made from six autoradiographic images that contained the region.

Measurement of Blood:Brain Partition Coefficient for Iodo $\left[{ }^{14} \mathrm{C}\right]$ Antipyrine in Rabbit. In vivo. The procedures used were similar to those of other investigators who have determined the partition coefficient for iodo $\left[{ }^{14} \mathrm{C}\right]$ antipyrine in newborn or 7-d-old rats $(5$, 9). Urethane anesthetized rabbits ( 1 or $8 \mathrm{~d}$ old) were prepared as described above and a bolus of tracer $\left(9.25 \mathrm{MBq} / \mathrm{kg}\right.$ iodo $\left[{ }^{14} \mathrm{C}\right]$ antipyrine) in saline was injected i.v. One $h$ later (i.e. approaching steady state conditions), an arterial blood sample was withdrawn and the animal was immediately decapitated. Multiple $20-\mu \mathrm{L}$ samples of the blood were processed for the determination of the concentration of iodo $\left[{ }^{14} \mathrm{C}\right]$ antipyrine. The brain was removed, frozen, and subsequently several samples of brain were weighed, digested with Scintigest, and analyzed in a scintillation counter. The homogeneity of the distribution of tracer throughout the brain was verified by exposing several cryostat sections of the frozen brain to $x$-ray film.

The brain:blood partition coefficient for iodo $\left[{ }^{14} \mathrm{C}\right]$ antipyrine was calculated as: [concentration of tracer in brain $(\mathrm{kBq} / \mathrm{mg})$ ]/ [concentration of tracer in blood $(\mathrm{kBq} / \mathrm{mL})$ ] under near equilibrium conditions.

In vitro. The partition coefficient for iodo $\left[{ }^{14} \mathrm{C}\right]$ antipyrine was also measured by incubating samples of brain in blood that contained tracer. Fresh heparinized rabbit blood (2-4 mL) was poured into scintillation vials and iodo $\left[{ }^{14} \mathrm{C}\right]$ antipyrine was added and mixed $(18.5-185 \mathrm{kBq})$. Then, cubes of brain $(50-75 \mathrm{mg})$ were also placed in the vials. The blood and tissue samples were shaken continuously at $37^{\circ} \mathrm{C}$ for approximately $2 \mathrm{~h}$ at which time several samples of arterial blood $(20 \mu \mathrm{L})$ and the sample of the brain (without blood) were processed for scintillation counting analysis. The homogeneity of the distribution of tracer in some of the samples was verified by producing $\mathrm{x}$-ray film autoradiograms of sections of the tissue before measuring tracer concentrations.

All results are reported as mean $\pm \mathrm{SEM}$ and statistical com- parisons were performed with PC-based statistics software (SAS, Cary, NC). Comparisons between groups were made using an analysis of variance with a Scheffe comparison of means. The overall dependence of cerebral blood flow on age was assessed with a general linear models analysis of variance. The interregional dependence of the response was assessed with a repeated measures analysis of variance that considered different regional measures as a repeated measure in the same animal.

\section{RESULTS}

Partition coefficient between brain and blood. In vivo, The partition coefficient of brain:blood for iodo $\left[{ }^{14} \mathrm{C}\right]$ antipyrine was $0.58 \pm 0.04 \mathrm{mg} / \mathrm{mL}$ for the newborn rabbit. In vitro, the partition coefficient was $0.64 \pm 0.02$ for newborn and $0.60 \pm 0.03 \mathrm{mg} /$ $\mathrm{mL}$ for adult rabbit brain, respectively. An average partition coefficient of 0.6 was used in the calculation of cerebral blood flow.

Postnatal changes in brain growth and physiologic parameters. The brain of the newborn rabbit, which is relatively immature at birth, demonstrated extensive development postnatally. Between birth and adulthood, increases were observed in the size and degree of myelination present in the rabbit brain (Table 1). In addition, the periventricular germinal plate of proliferating cells was absent by $17 \mathrm{~d}$ postnatally.

There were also postnatal changes in several of the physiologic parameters monitored during the measurement of local cerebral blood flow. Arterial blood pressure and arterial $\mathrm{PO}_{2}$ rose above neonatal values during development, whereas arterial $\mathrm{PCO}_{2}$ fell (Table 2).

Postnatal changes in local cerebral blood flow. Local cerebral blood flow increased markedly after birth $(p<0.0001)$, with the largest elevations in cerebral blood flow occurring between 8 and $17 \mathrm{~d}$ of age (Fig. 1, Table 3). In general, there were significant differences in local cerebral blood flow between either newborn or 8-d-old rabbits and 17-d-old or older rabbits $(p<0.001)$.

The overall analysis of variance that considered different regions as a repeated measure in the same animal indicated that the postnatal changes in local cerebral blood flow were also dependent on the region examined $(p<0.0001)$. Subsequently, a comparison of the regional blood flow levels observed postnatally with those observed in newborns demonstrates clearly that the magnitude of the postnatal increases in cerebral blood flow are nonuniform regionally (Figs. 2-4). The most marked increases in flow (350-400\% of newborn) occurred in areas of the cerebral cortex, thalamus, and white matter. The least pronounced changes in flow occurred in medulla and pons (150$250 \%$ of newborn). The age at which flow was observed to attain its maximum was also dependent on the region examined-for example, $17 \mathrm{~d}$ of age for most thalamic regions, but $40 \mathrm{~d}$ of age for most cortical areas.

Table 1. Change with postnatal age in myelination, germinal matrix, and brain size in rabbit*

\begin{tabular}{|c|c|c|c|c|c|}
\hline & \multicolumn{5}{|c|}{ Postnatal age } \\
\hline & Newborn & $8 d$ & $17 d$ & $40 d$ & Adult \\
\hline Myelination $\dagger$ & $-/+$ & + & ++ & +++ & ++++ \\
\hline Germinal matrix $\ddagger$ & +++ & ++ & - & - & - \\
\hline $\begin{array}{l}\text { \% Mid-cross-sectional } \\
\text { area§ }\end{array}$ & $36 \pm 3$ & $49 \pm 4$ & $62 \pm 2$ & $72 \pm 2$ & $100 \pm 5$ \\
\hline
\end{tabular}

*-, not present; $-/+$, not present or sparse; + , sparse; ++ , moderate; or +++ , large amounts present.

$\uparrow$ As assessed by positive staining of white matter with Luxol fast blue. $\ddagger$ Periventricular plate of undifferentiated cells at the level of the striatum.

$\S$ Presented as a \% of the area in adult animals $\left(420 \mathrm{~mm}^{2}\right)$. 
Table 2. Changes during postnatal development in physiologic parameters monitored during measurement of local cerebral blood flow*

\begin{tabular}{|c|c|c|c|c|c|}
\hline & \multicolumn{5}{|c|}{ Postnatal age } \\
\hline & $\begin{array}{c}\text { Newborn } \\
(n=5)\end{array}$ & $\begin{array}{c}8 \mathrm{~d} \\
(n=5)\end{array}$ & $\begin{array}{c}17 \mathrm{~d} \\
(n=4)\end{array}$ & $\begin{array}{c}40 \mathrm{~d} \\
(n=4)\end{array}$ & $\begin{array}{l}\text { Adult } \\
(n=4)\end{array}$ \\
\hline Temperature $\left({ }^{\circ} \mathrm{C}\right)$ & $37.8 \pm 0.3$ & $38.3 \pm 0.3$ & $38.9 \pm 0.1 \dagger$ & $38.1 \pm 0.2$ & $38.7 \pm 0.1$ \\
\hline Weight (g) & $62 \pm 4$ & $142 \pm 9$ & $432 \pm 21$ & $746 \pm 16+$ & $.3550 \pm 210 \S$ \\
\hline $\begin{array}{l}\text { Mean arterial blood pressure }[\mathrm{kPa} \\
(\mathrm{mm} \mathrm{Hg})]\end{array}$ & $4.4 \pm 0.4(33)$ & $6.0 \pm 0.4(45)$ & $7.6 \pm 0.5(57)$ & $11.4 \pm 0.3(86) \S$ & $12.8 \pm 0.7(96) \S$ \\
\hline Heart rate $\left(\mathrm{s}^{-1}\right)$ & $4.88 \pm 0.3$ & $5.18 \pm 0.3$ & $5.75 \pm 0.17$ & $6.1 \pm 0.07$ & $5.3 \pm 0.25$ \\
\hline Arterial $\mathrm{PCO}_{2}[\mathrm{kPa}(\mathrm{mm} \mathrm{Hg})]$ & $7.8 \pm 0.1(59)$ & $7.8 \pm 0.4(59)$ & $6.7 \pm 0.3(50)$ & $6.7 \pm 0.3(50)$ & $5.0 \pm 0.4(38) \S$ \\
\hline Arterial $\mathrm{PO}_{2}[\mathrm{kPa}(\mathrm{mm} \mathrm{Hg})]$ & $5.3 \pm 0.4(40)$ & $7.0 \pm 0.5(53) \dagger$ & $9.6 \pm 0.4(72) \frac{\dot{1}}{\div}$ & $8.6 \pm 0.5(65) \dagger$ & $10.0 \pm 0.1(75) \ddagger$ \\
\hline Arterial pH & $7.31 \pm 0.01$ & $7.32 \pm 0.02$ & $7.38 \pm 0.02$ & $7.40 \pm 0.03$ & $7.40 \pm 0.04$ \\
\hline
\end{tabular}

* All values presented as mean \pm SEM.

$\dagger p<0.05$, different from newborn animals.

$+p<0.05$, different from newborn and 8- $\alpha$-old animals.

$\$ p<0.05$, different from newborn, 8- and 17-d-old animals.

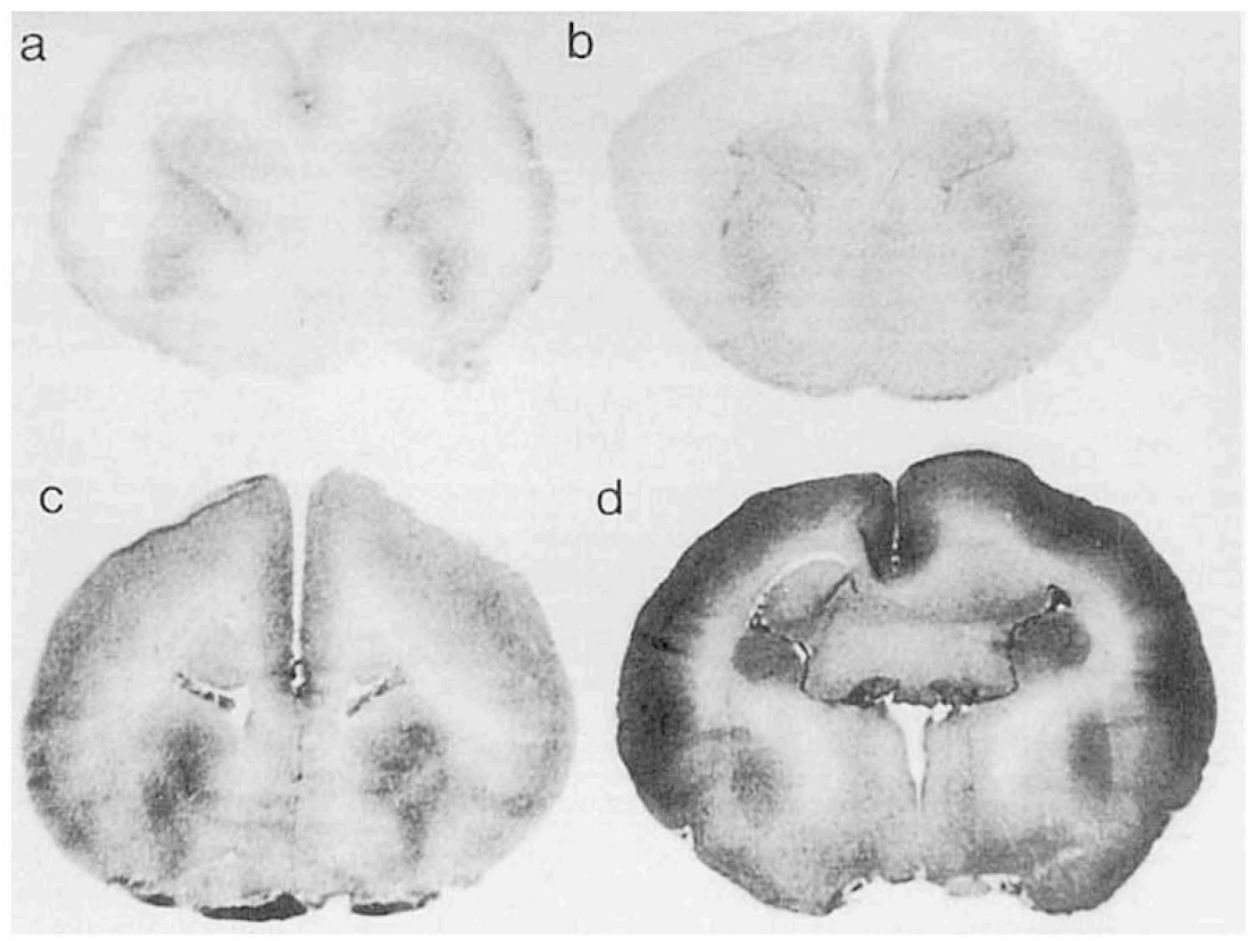

Fig. 1. Cerebral blood flow autoradiograms during postnatal development in the rabbit. Gray levels in all four autoradiograms depict equivalent levels of blood flow, the darkest areas representing the highest levels of blood flow. Autoradiograms are from coronal sections at the level of the striatum in rabbits of different postnatal ages: $1 \mathrm{~d}(a), 8 \mathrm{~d}(b), 17 \mathrm{~d}(c)$, and adult $(d)$. Cerebral blood flow in 17-d-old and adult rabbits is markedly higher than in newborn rabbits.

\section{DISCUSSION}

The present study demonstrates that the newborn rabbit is an appropriate animal model in which to study the local control of the cerebral circulation with quantitative autoradiographic techniques. In the newborn rabbit, as in other relatively immature species at birth, local cerebral blood flow is low relative to levels observed in the adult. Furthermore, cerebral blood flow in the newborn is heterogeneous locally, and the differential hierarchy of blood flow between regions alters postnatally.

Rabbit as Perinatal Animal Model. Its small size, year round availability, and short gestation $(\sim 32 \mathrm{~d})$ make the rabbit a readily available, inexpensive model in which to study the cerebral circulation in the perinatal period. In addition, several aspects of its anatomy and development make this species attractive as a model in medical research.

The newborn rabbit is large enough to allow a modest degree of physiologic manipulation and sampling of blood. Catheters may be inserted into the femoral vesseis in order to measure arterial blood pressure, sample blood for arterial gases, and infuse drugs or fluids i.v. Such measurements are necessary so various factors that influence the cerebral circulation are monitored and/ or controlled. Furthermore, to measure cerebral blood flow with a high-resolution, quantitative autoradiographic technique, arterial and venous catheters are required to infuse the tracer i.v. and to measure the arterial concentration of tracer during infusion.

The rabbit is immature at birth, with almost all myelination occurring postnatally. In the present study, we found that myelin staining was absent or sparse at birth and increased markedly between 8 and 40 d of age. Similarly, Wender et al. (10) have reported that, in rabbits, myelin staining is sparse at $3 \mathrm{~d}$ of age, more advanced at $10 \mathrm{~d}$ of age, and characteristic of adult staining but incomplete at $30 \mathrm{~d}$ of age. Myelin-associated lipids (e.g. cerebrosides) increase markedly after birth in the rabbit, the peak accumulation rate occurring between 3 and $20 \mathrm{~d}$ after birth (11- 
Table 3. Local cerebral blood flow in various brain regions at different postnatal ages in rabbit (mean $\pm S E M)$

\begin{tabular}{|c|c|c|c|c|c|}
\hline \multirow[b]{2}{*}{ Brain region } & \multicolumn{5}{|c|}{ Local cerebral blood flow $\left[\mathrm{mL} \cdot \mathrm{kg}^{-1} \cdot \mathrm{s}^{-1}\left(\mathrm{~mL} \cdot 100 \mathrm{~g}^{-1} \cdot \mathrm{min}^{-1}\right)\right]$} \\
\hline & $\begin{array}{c}\text { Newborn } \\
(n=5)\end{array}$ & $\begin{array}{c}8-d \\
(n=5)\end{array}$ & $\begin{array}{c}17-\mathrm{d} \\
(n=4)\end{array}$ & $\begin{array}{c}40-d \\
(n=4)\end{array}$ & $\begin{array}{c}\text { Adult } \\
(n=4)\end{array}$ \\
\hline \multicolumn{6}{|l|}{ Cerebellum/brainstem } \\
\hline Cerebellar cortex & $3.5 \pm 0.5(21)$ & $3.3 \pm 0.3(20)$ & $9.4 \pm 1.7(56)^{*}$ & $13.9 \pm 0.7(83)^{*}$ & $10.4 \pm 1.7(62)^{*}$ \\
\hline Cerebellar white matter & $2.2 \pm 0.5(13)$ & $2.3 \pm 0.3(14)$ & $6.7 \pm 0.8(40)^{*}$ & $5.8 \pm 0.8(35)^{*}$ & $4.2 \pm 0.7(25)$ \\
\hline Inferior olivary nucleus & $8.5 \pm 1.3(51)$ & $9.9 \pm 1.5(59)$ & $19.4 \pm 1.0(116)^{*}$ & $20.4 \pm 1.7(122)^{*}$ & $12.4 \pm 2.2(74)$ \\
\hline Nucleus tractus solitarius & $8.9 \pm 1.5(53)$ & $8.5 \pm 1.5(51)$ & $15.2 \pm 0.3(91)^{*}$ & $13.7 \pm 0.8(82)$ & $11.0 \pm 1.7(66)$ \\
\hline Medullary reticular formation & $8.9 \pm 1.9(53)$ & $8.7 \pm 0.9(52)$ & $14.8 \pm 0.2(88)$ & $12.7 \pm 0.5(76)$ & $9.9 \pm 1.0(59)$ \\
\hline Vestibular nucleus & $8.6 \pm 1.5(51)$ & $9.6 \pm 1.5(57)$ & $20.8 \pm 1.5(124)^{*}$ & $24.5 \pm 1.7(146)^{*}$ & $15.4 \pm 2.8(92)$ \\
\hline Pontine reticular formation & $4.9 \pm 0.8(29)$ & $6.7 \pm 1.0(40)$ & $11.9 \pm 0.5(71)^{*}$ & $10.1 \pm 1.0(60)^{*}$ & $8.6 \pm 1.0(51)$ \\
\hline Dorsal tegmental nucleus & $7.4 \pm 1.0(44)$ & $8.2 \pm 1.5(49)$ & $19.3 \pm 2.7(115)^{*}$ & $15.9 \pm 0.8(95)^{*}$ & $12.7 \pm 2.0(76)$ \\
\hline \multicolumn{6}{|l|}{ Diencephalon } \\
\hline Lateral habenular nucleus & $5.0 \pm 1.0(30)$ & $5.5 \pm 1.0(33)$ & $15.6 \pm 2.0(93)^{*}$ & $17.9 \pm 1.2(107)^{*}$ & $14.9 \pm 3.2(89)^{*}$ \\
\hline Medial geniculate body & $4.7 \pm 0.7(28)$ & $5.4 \pm 0.8(32)$ & $12.7 \pm 0.8(76) \dagger$ & $16.6 \pm 2.3(99)^{*}$ & $15.1 \pm 2.9(90)^{*}$ \\
\hline Ventroposterior thalamic nucleus & $2.9 \pm 0.5(13)$ & $3.5 \pm 0.7(21)$ & $8.7 \pm 0.5(52)^{*}$ & $8.9 \pm 1.0(53)^{*}$ & $7.5 \pm 0.7(45)^{*}$ \\
\hline Anteroventral thalamic nucleus & $3.5 \pm 0.5(21)$ & $4.5 \pm 0.8(27)$ & $13.2 \pm 1.2(79)^{*}$ & $14.1 \pm 2.1(84)^{*}$ & $12.7 \pm 2.1(76)^{*}$ \\
\hline Lateral geniculate nucleus & $2.9 \pm 0.5(17)$ & $4.2 \pm 0.8(25)$ & $10.9 \pm 0.7(65)^{*}$ & $12.6 \pm 1.2(75)^{*}$ & $9.4 \pm 1.2(56)^{*}$ \\
\hline Hypothalamus & $3.5 \pm 0.5(21)$ & $4.7 \pm 0.5(28)$ & $10.2 \pm 0.5(61)^{*}$ & $8.0 \pm 1.3(48)^{*}$ & $7.7 \pm 1.0(46)^{*}$ \\
\hline Corpus callosum & $1.0 \pm 0.3(6)$ & $1.3 \pm 0.3(8)$ & $3.5 \pm 0.3(21)^{*}$ & $3.7 \pm 0.8(22)^{*}$ & $3.2 \pm 0.2(19)^{*}$ \\
\hline \multicolumn{6}{|l|}{ Telencephalon } \\
\hline Anterior cingulate cortex & $3.2 \pm 0.3(19)$ & $3.5 \pm 0.5(21)$ & $8.6 \pm 0.7(51)^{*}$ & $12.6 \pm 1.0(75)^{*}$ & $12.1 \pm 1.7(72)^{*}$ \\
\hline Parietal cortex & $2.5 \pm 0.5(15)$ & $3.0 \pm 0.5(18)$ & $6.5 \pm 0.3(39)^{*}$ & $10.6 \pm 1.3(63)^{*}$ & $10.6 \pm 1.3(63)^{*}$ \\
\hline Sensory motor cortex & $3.3 \pm 0.7(20)$ & $3.3 \pm 0.5(20)$ & $7.9 \pm 0.3(47)$ & $12.6 \pm 1.2(81)^{*}$ & $13.4 \pm 2.1(80)^{*}$ \\
\hline Frontal cortex & $3.4 \pm 0.7(20)$ & $3.4 \pm 0.5(20)$ & $7.7 \pm 0.7(46)^{*}$ & $10.7 \pm 0.5(64)^{*}$ & $11.2 \pm 1.8(67)^{*}$ \\
\hline Visual cortex & $2.9 \pm 0.5(17)$ & $2.9 \pm 0.5(17)$ & $6.4 \pm 0.3(38)$ & $9.4 \pm 0.7(56)^{*}$ & $11.6 \pm 2.0(69)^{*}$ \\
\hline Dentate gyrus & $3.0 \pm 0.5(18)$ & $4.0 \pm 0.7(24)$ & $9.1 \pm 0.8(54)^{*}$ & $7.2 \pm 0.5(43)^{*}$ & $8.6 \pm 1.3(51)^{*}$ \\
\hline Amygdala & $2.2 \pm 0.3(13)$ & $3.7 \pm 0.7(22)$ & $7.5 \pm 0.3(45)^{*}$ & $6.7 \pm 0.8(40)^{*}$ & $6.4 \pm 0.8(38)^{*}$ \\
\hline Caudate nucleus & $3.2 \pm 0.3(19)$ & $4.0 \pm 0.7(24)$ & $10.1 \pm 0.3(60)^{*}$ & $11.4 \pm 0.8(68)^{*}$ & $10.1 \pm 1.3(60)^{*}$ \\
\hline Septal nucleus & $2.5 \pm 0.3(15)$ & $3.0 \pm 0.5(18)$ & $7.7 \pm 0.3(46)^{*}$ & $7.7 \pm 1.2(46)^{*}$ & $7.2 \pm 0.3(43)^{*}$ \\
\hline Globus pallidus & $2.2 \pm 0.3(13)$ & $3.0 \pm 0.3(18)$ & $7.0 \pm 0.3(42)^{*}$ & $6.4 \pm 0.8(38)^{*}$ & $7.2 \pm 0.8(43)^{*}$ \\
\hline Body of the genu & $1.0 \pm 0.2(6)$ & $1.5 \pm 0.3(9)$ & $4.4 \pm 0.3(26)^{*}$ & $4.0 \pm 0.5(24)^{*}$ & $4.2 \pm 0.5(25)^{*}$ \\
\hline Periventricular & $3.2 \pm 0.5(19)$ & $3.0 \pm 0.5(18)$ & $7.4 \pm 0.3(44)^{*}$ & $9.7 \pm 0.5(58)^{*}$ & $9.7 \pm 1.2(58)^{*}$ \\
\hline
\end{tabular}

$* p<0.05$, different from newborn and 8-d-old animals.

$+p<0.05$, different from newborn animals.

13), with maximal levels being attained by approximately $120 \mathrm{~d}$ postnatally.

A majority of the rabbit's brain growth also occurs postnatally. In the present study, the cross-sectional area of the midcerebrum increased 3- to 4-fold postnatally. This corresponds well with the 5 - to 7 -fold increase in brain weight reported by others $(12,13)$. The rate of growth of rabbit cerebrum attains a peak (i.e. a growth spurt) at approximately $8 \mathrm{~d}$ after birth. The newborn rat also experiences a brain growth spurt approximately $1 \mathrm{wk}$ after birth, whereas the human differs somewhat by exhibiting a brain growth spurt at the end of gestation. In marked contrast, other species such as monkey, guinea pig, and sheep have completed a major part of their brain growth by birth (14). Thus, in comparison to man, the rabbit may provide a useful model in which to study the effects of premature birth by the comparison of responses in newborn and older rabbits postnatally.

The cerebral circulation of the rabbit is similar anatomically to that of the human. The blood is supplied to the rabbit brain by two internal carotid and vertebral arteries. The basilar artery joins the circle of Willis at the base of the brain (15). This supply of the cerebral circulation differs from the cerebral circulations of the lamb and cat, which both have a rete mirabile, and of the dog, which obtains a substantial amount of its cerebral blood supply via external carotid arteries (16).

Increases in Cerebral Blood Flow Postnatally. Regional or global cerebral blood flow has been investigated in rabbits by other laboratories; however, the present study is the first to perform a comprehensive investigation covering ages ranging from newborn to adult. Pardridge and Mietus (17) measured blood flow in the cerebrum of newborn rabbits with ${ }^{14} \mathrm{C}$-butanol and obtained a value of $4.2 \mathrm{~mL} \cdot \mathrm{kg}^{-1} \cdot \mathrm{s}^{-1}\left(25 \mathrm{~mL} \cdot 100 \mathrm{~g}^{-1} \cdot \mathrm{min}^{-1}\right)$,

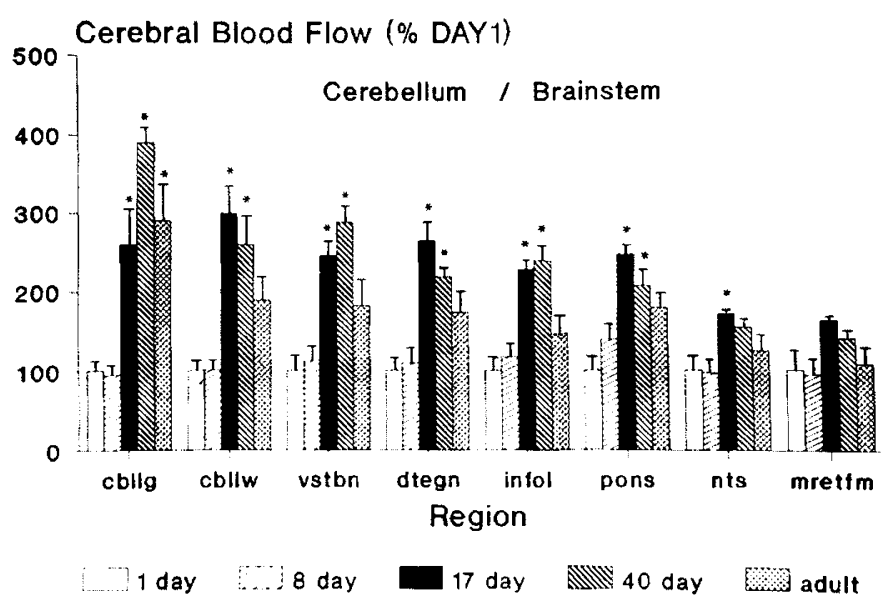

Fig. 2. Relationship between local cerebral blood flow and postnatal age for regions within the cerebellum and brainstem. Blood flow for each region is presented as a percentage of mean blood flow in the newborn animals for that region. Postnatally, there are modest $(50-200 \%)$ increases in blood flow in the brainstem and marked (200-300\%) increases in blood flow in the cerebellum. Maximal levels of flow are attained at either 17 or $40 \mathrm{~d}$ of age. cbllg, cerebellar gray; cbllw, cerebellar white; vstbn, vestibular nucleus; dtegn, dorsal tegmental nucleus; infol, inferior olive; pons, pontine reticular formation; $n t s$, nucleus tractus solitarius; mretfm, medullary reticular formation. ${ }^{*}, p<0.05$, different from newborn or 8-d-old animals. 


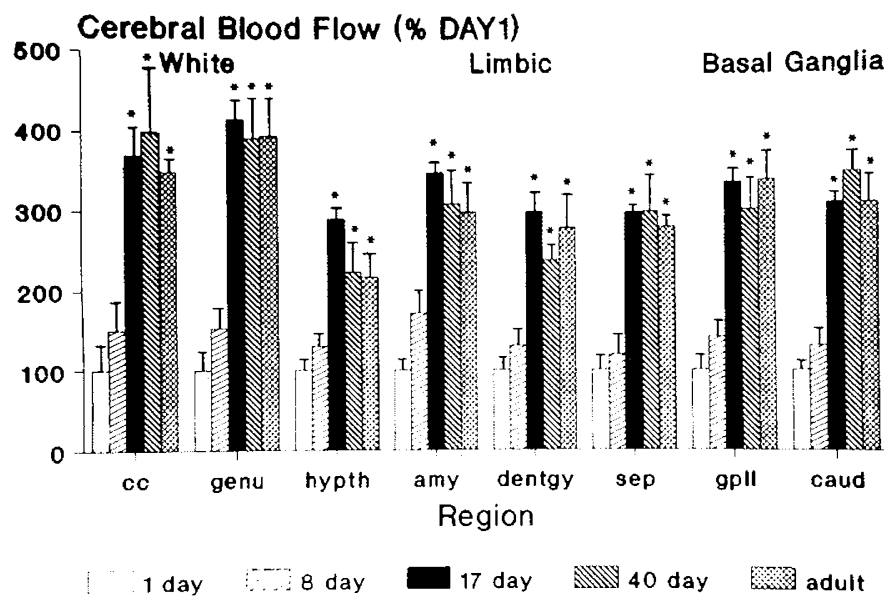

Fig. 3. Relationship between local cerebral blood flow and postnatal age for regions within white matter, limbic regions, and the basal ganglia. Blood flow for each region is presented as a percentage of that in newborn rabbits. Postnatally, there are marked increases in local cerebral blood flow of $200-300 \%$ with maximal levels of flow being attained by $17 \mathrm{~d}$ of age. $c c$, corpus callosum; genu, body of the genu; hypth, hypothalamus; amy, amygdala; dentgy, dentate gyrus; sep, septal; gpll, globus pallidus; cand, caudate nucleus. ${ }^{*}, p<0.05$, different from 1- or 8-d-old animals.

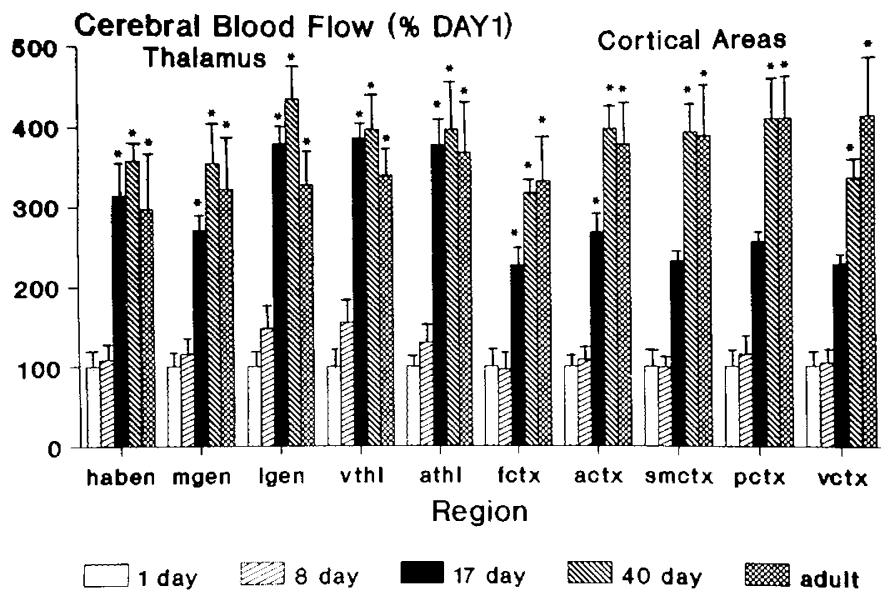

Fig. 4. Relationship between local cerebral blood flow and postnatal age for regions within thalamic and cortical regions. Blood flow for each region is presented as a percentage of mean blood flow for that region in newborn rabbits. Postnatally, there are pronounced (250-350\%) increases in local cerebral blood flow. Maximal levels of blood flow are attained by $40 \mathrm{~d}$ of age within the thalamus and not until adulthood within the cortical areas. haben, habenular nucleus; mgen, medical geniculate body; lgen, lateral geniculate body; vthl, ventrolateral thalamus; $a t h l$, anterior thalamus; $f(t x$, frontal cortex; $a c t x$, anterior cingulate cortex; smctx, sensory motor cortex; pctx, parietal cortex; $v c t x$, visual cortex. ${ }^{*}, p<0.05$, different from newborn or 8 -d-old animals.

which is similar to that in the present study. Studies in which cerebral blood flow was measured with the hydrogen clearance technique obtained values of blood flow within the cerebral cortex of approximately $10 \mathrm{~mL} \cdot \mathrm{kg}^{-1} \cdot \mathrm{s}^{-1}\left(60 \mathrm{~mL} \cdot 100 \mathrm{~g}^{-1} \cdot \mathrm{min}^{-1}\right)$ in 2-wk-old rabbits $(18)$ and $16 \mathrm{~mL} \cdot \mathrm{kg}^{-1} \cdot \mathrm{s}^{-1}\left(95 \mathrm{~mL} \cdot 100 \mathrm{~g}^{-1}\right.$. $\mathrm{min}^{-1}$ ) in adult rabbits (19). In adult rabbits in which cerebral blood flow was measured with microspheres, cortical blood flow was $7.5-11 \mathrm{~mL} \cdot \mathrm{kg}^{-1} \cdot \mathrm{s}^{-1}\left(45-65 \mathrm{~mL} \cdot 100 \mathrm{~g}^{-1} \cdot \mathrm{min}^{-1}\right)(20,21)$. Considering the differences in methods used, these values are comparable to blood flow values within the cerebral cortex observed in the present study $\left[6.5-20 \mathrm{~mL} \cdot \mathrm{kg}^{-1} \cdot \mathrm{s}^{-1}(40-50 \mathrm{~mL}\right.$. $\left.100 \mathrm{~g}^{-1} \cdot \mathrm{min}^{-1}\right)$ in 17 -d-old rabbits and $10-12 \mathrm{~mL} \cdot \mathrm{kg}^{-1} \cdot \mathrm{s}^{-1}(60-$ $70 \mathrm{~mL} \cdot 100 \mathrm{~g}^{-1} \cdot \mathrm{min}^{-1}$ ) in adults].

The present direct comparison of cerebral blood flow at various postnatal ages and under equivalent conditions demonstrates that blood flow increases $50-300 \%$ during postnatal development in the rabbit. Similar postnatal increases in cerebral blood flow have been observed in other species. In rats, cerebral blood flow measured with iodo $\left[{ }^{14} \mathrm{C}\right]$ antipyrine autoradiography also increased up to $300 \%$ during the period from $10 \mathrm{~d}$ of age into adulthood (6). In the newborn dog, cerebral blood flow measured with ${ }^{14} \mathrm{C}$-antipyrine autoradiography increased markedly (up to 4-fold) in the first $7 \mathrm{wk}$ after birth. After cerebral blood flow reached a peak between 30 and $50 \mathrm{~d}$ of age, it then declined, attaining levels in the adult that remained greater than those in the newborn (1). The age at which local blood flow peaked depended on the region examined-a response also observed presently in the rabbit. Studies of human subjects have measured either cerebral blood velocity or tissue blood flow and have observed 3- to 4-fold increases during development, with a peak in flow being observed in children of 5-6 y of age (22-24). Thus, rabbit, dog, rat, and man all demonstrate postnatal increases in cerebral blood flow, and all have a brain that is relatively immature at birth. In contrast, species such as monkey or sheep, which are well developed at birth (14), have similar or higher levels of cerebral blood flow in the newborn compared with the adult $(25-27)$.

Heterogeneity of Local Cerebral Blood Flow. Blood flow in the newborn rabbit brain was heterogeneous, with flow varying widely from a low of $1 \mathrm{~mL} \cdot \mathrm{kg}^{-1} \cdot \mathrm{s}^{-1}$ in white matter to a high of $9 \mathrm{~mL} \cdot \mathrm{kg}^{-1} \cdot \mathrm{s}^{-1}$ in the medulla. Blood flow variations within the cerebrum itself were less marked, inasmuch as maximal blood flow in gray matter such as the cerebral cortex and striatum was approximately $3.3 \mathrm{~mL} \cdot \mathrm{kg}^{-1} \cdot \mathrm{s}^{-1}$. Indeed, previous investigators have concluded that blood flow in the newborn brain is rather homogeneous regionally $(1,6)$. However, even within the cerebrum, the ratio between gray and white matter was a factor of 3 to 5 , and a similar gray/white ratio has been observed in immature newborn species such as dog, rat, and human $(1,2,5,28)$. Thus, despite modest absolute flow differences within the cerebrum of the newborn, there are rather large relative differences in flow locally. Potential factors contributing to the regional differences in local blood flow are discussed below.

Factors Influencing Postnatal Blood Flow. Arterial blood pressure. Mean arterial blood pressure increased from an average of 4.4 to $12.8 \mathrm{kPa}$ (33 to $96 \mathrm{~mm} \mathrm{Hg}$ ) during postnatal development. Thus, the elevation in perfusion pressure may be responsible, at least in part, for the generalized increase in brain blood flow observed in more mature animals. Clearly, other factors are also involved, inasmuch as the increases in cerebral blood flow were not uniform within the different brain structures. For example, comparing newborn and adult rabbits, although the systemic elevations in blood pressure are common to all brain regions, blood flow in the medulla increased only modestly during postnatal development, whereas that in the cerebral cortex increased 4-fold.

Similar to that in the adult, cerebral blood flow has been found to be maintained near constant during moderate changes in perfusion pressure in various newborn animals and in human subjects $(2,29-31)$. Because, in the present study, within each age group and for each region there appeared to be a different basal level of blood flow, it is likely that autoregulation of cerebral blood flow adapts to elevated levels of flow and blood pressure during development. Indeed, in a study of cerebral blood flow autoregulation in the newborn dog, there appeared to be a shift in the pressure limits of autoregulation of global cerebral blood flow to a lower pressure range compared with the adult (29). A similar effect has been observed during chronic hypertension where there is an adaptation of the cerebral autoregulatory range to the chronic higher blood pressure levels (32).

Anesthesia. Local cerebral blood flow was measured in rabbits that were anesthetized with urethane, raising the possibility that regional differences in flow were due to differential regional effects of anesthesia. However, evidence indicates that the general 
pattern of local cerebral blood flow does not alter markedly with urethane anesthesia. The general hierarchy of blood flow levels measured in the adult urethane-anesthetized rabbits is equivalent to that reported in awake adult rabbits $(20,21)$ and similar to that in awake rats (33). Furthermore, we have recently measured local cerebral blood flow in awake newborn $(n=2)$ or 8 -d-old $(n=2)$ rabbits, and the pattern of cerebral blood flow in these conscious animals is analogous to that in the anesthetized animals of the present study (e.g. brainstem blood flow is greater than that in the cerebral cortex) (unpublished results). Further experiments are required to determine the extent to which cerebral blood flow is depressed by urethane anesthesia.

Blood gases. In the present study, newborn rabbits were relatively hypercapnic and hypoxic compared with adult animals. It is possible that, similar to those in newborn rats or dogs, the blood gases observed in the young rabbits are near normal (1, 34). This is supported by the fact that in a separate group of awake newborn $(n=7)$ and 8 -d-old $(n=5)$ rabbits, blood gases were equivalent to those in the present study $\left[\mathrm{PaCO}_{2}=7.6 \pm 0.4\right.$ $\mathrm{kPa}(57 \mathrm{~mm} \mathrm{Hg}), \mathrm{PaO}_{2}=6.4 \pm 0.6 \mathrm{kPa}(48 \mathrm{~mm} \mathrm{Hg})$ in newborns and $\mathrm{PaCO}_{2}=7.0 \pm 0.2 \mathrm{kPa}(52 \mathrm{~mm} \mathrm{Hg}), \mathrm{PaO}_{2}=7.0 \pm 0.5 \mathrm{kPa}$ $(52 \mathrm{~mm} \mathrm{Hg})$ in 8-d-old rabbits, respectively]. Because a high $\mathrm{PaCO}_{2}$ is a well-documented vasodilator in both adult and newborn animals, differences in blood gases do not explain postnatal increases in cerebral blood flow. However, the decline in arterial $\mathrm{PCO}_{2}$ with age may play a role in interregional differences in flow if regional differences in $\mathrm{CO}_{2}$ reactivity exist at different postnatal ages.

Microvascular anatomy. Regional differences in local capillary density and thus local cerebrovascular resistance account for some of the regional variation in local cerebral blood flow within the brain (35-37). Furthermore, increases in capillary density occur postnatally $(35,37,38)$. Thus, local alterations in the microvasculature during development likely contribute to both the interregional and absolute increases in cerebral blood flow observed during development.

Local metabolism. One of the most important factors likely determining the local level of blood flow within the brain is the local energy demands of the tissue for cell maintenance, growth, differentiation, myelination, and functional activity. As discussed by other investigators $(1,6)$, this is supported by the close correlation between the postnatal changes observed in local cerebral blood flow with increases in local oxygen metabolism, glucose utilization, and alterations in energy consuming processes within the brain during development in species such as rat, dog, monkey, and man.

In the present study of the rabbit, the pattern of cerebral blood flow in the newborn differs substantially from that in the adult. For example, in the newborn rabbit, blood flow in the hypothalamus is greater than that in the visual cortex, whereas in the adult rabbit blood flow in the visual cortex exceeds that in the hypothalamus. Similar developmental changes in regional hierarchy have been observed in the visual cortex and the (anterolateral) hypothalamus in the unanesthetized rat and dog, respectively $(1,6)$. These differential patterns of flow in the newborn compared with the adult likely reflect, at least in part, differences in the rate of maturation of the different regions. For example, blood flow in the rabbit brainstem is relatively mature at birth, and this corresponds well with the demonstration that the brainstem, diencephalon, and telencephalon develop sequentially (as indicated by the appearance of EEG potentials and the range of motor behavior possible) (39). In the rabbit, the relatively advanced maturity of the brainstem at birth may also be reflected in the higher concentrations of muscarinic and methionineenkephalin binding sites reported in the brainstem compared with the cerebral cortex or caudate nucleus $(40,41)$. During development of the visual or sensory motor cortex, synaptogenesis starts at $\mathrm{d} 6$ to 7 , is greatest between $\mathrm{d} 10$ and 21 , and synaptic density and dendritic spinal density exceed adult levels (in the visual cortex) at $d 26$ or $27(42,43)$. Electrophysiologic experiments have shown that the action potentials recorded from predominantly thalamic cells in urethane-anesthetized rabbits increase their frequency of firing at $14 \mathrm{~d}$, attain adult levels at 30 $\mathrm{d}$, and exceed adult levels at $70 \mathrm{~d}$ of age (44). Behaviorally, the rabbit has poor walking and righting skills, which mature within the first $14 \mathrm{~d}$. Between 14 and $21 \mathrm{~d}$ of age, the rabbit commences hopping with all locomotion subsequently converting to hopping (45). Eye opening occurs between d 8 and 14 , weaning at approximately $40 \mathrm{~d}$, and puberty at approximately $80 \mathrm{~d}(44,45)$. Thus, in the rabbit, the marked increases in cerebral blood flow observed between 8 and $17 \mathrm{~d}$ of age occur at a time of marked maturational advances in anatomy, electrophysiology, and behavior. Depending on the region examined, increases in cerebral blood flow and maturation continue subsequently. Further experiments are required to determine the exact extent to which arterial blood pressure, microvascular anatomy, and local metabolism contribute to postnatal increases in local cerebral blood flow and to determine the effect of superimposed stimuli such as a decrease in arterial $\mathrm{PCO}_{2}$ or anesthesia.

Implications for Cerebral Pathophysiology in Neonate. The striking dependence of regional cerebral blood flow on postnatal age suggests that the local control of the cerebral circulation also differs markedly at different stages of development. With respect to ischemia, the threshold flow level for damage will likely depend on the basal level of flow. Evidence in the human neonate suggests that the blood flow threshold for brain damage is lower in the neonate than in the adult (46). Although regional thresholds for ischemic damage in the neonate have not yet been determined, the distinct heterogeneous pattern of blood flow present in the newborn suggests that the ischemic thresholds for damage may also vary locally within the brain.

Acknowledgment. The author thanks S. Bascaramurty for excellent technical assistance.

\section{REFERENCES}

1. Kennedy C, Grave GD, Jehle JW, Sokoloff L 1972 Changes in blood flow in the component structures of the dog brain during postnatal maturation. $J$ Neurochem 19:2423-2433

2. Pasternak JF, Groothius DR 1985 Autoregulation of cerebral blood flow in the newborn beagle puppy. Biol Neonate 48:100-109

3. Ment LR, Stewart WB, Duncan CC, Pitt BR 1986 Beagle puppy model of cerebral insults: cerebral blood flow changes and intraventricular hemorrhage evoked by hypoxemia. J Neurosurg 65:847-850

4. Anwar M, Vannucci RC 1988 Autoradiographic determination of regional cerebral blood flow during hypoglycemia in newborn dogs. Pediatr Res 24:41-45

5. Lyons DT, Vasta F, Vannuci RC 1987 Autoradiographic determination of regional cerebral blood flow in the immature rat. Pediatr Res $21: 471-476$

6. Nehlig A, de Vasconcelos PA, Boyet S 1989 Postnatal changes in local cerebral blood flow measured by the quantitative autoradiographic $\left[{ }^{14} \mathrm{C}\right]$ iodoantipyrine technique in freely moving rats. $\mathrm{J}$ Cereb Blood Flow Metab 9:579-588

7. Sakurada O, Kennedy C, Jehle J, Brown JD, Carbin GL, Sokoloff L 1978 Meausrement of local cerebral blood flow with iodo $\left[{ }^{14} \mathrm{C}\right]$ antipyrine. Am J Physiol 234:H59-H66

8. Tuor UI 1990 Local distribution of the effects of sympathetic stimulation on cerebral blood flow in the rat. Brain Res 529:224-231

9. Fuisgang A, Lomholt M, Gjedde A 1986 Blood-brain transfer of glucose and glucose analogs in newborn rats. J Neurochem 46:1417-1428

10. Wender M, Kozik M, Mularek O 1975 Histochemistry of oxidative enzymes in the neuroglia in course of myelination. Acta Anat (Basel) 91:83-96

11. Dalal KB, Einstein ER 1969 Biochemical maturation of the central nervous system. I. Lipid changes. Brain Res 16:441-451

12. Harel S, Watanabe K, Linke I, Schain RJ 1972 Growth and development of rabbit brain. Biol Neonate 21:381-399

13. Odutuga AA, Carey EM, Prout RES 1973 Changes in the lipid and fatty acid composition of developing rabbit brain. Biochim Biophys Acta 316:115-123

14. Dobbing J, Sands J 1979 Comparative aspects of the brain growth spurt. Early Hum Dev 3:79-83

15. Scremin OU, Sonnenschein RR, Rubinstein EH 1982 Cerebrovascular anatomy and blood flow measurements in the rabbit. J Cereb Blood Flow Metab $2: 55-66$

16. Jennett B, Miller J Harper A 1976 Anatomy of the collateral cerebral circulation in man and animals. In: Jennett B, Miller J, Harper A (eds) Effect of Carotid Artery Surgery on Cerebral Blood Flow. Elsevier Biomedical Press, Amsterdam, pp 21-39

17. Pardridge WM, Mietus LJ 1980 Transport of thyroid and steroid hormones 
through the blood-brain barrier of the newborn rabbit: primary role of protein-bound hormone. Endocrinology 107:1705-1710

18. Koyama K, Mito T, Takashima S, Suzuki S 1990 Effects of phenylephrine and dopamine on cerebral blood flow, blood volume, and oxygenation in young rabbits. Pediatr Neurol 6:87-90

19. Tuor UI, Farrar JK 1984 Pial vessel caliber and cerebral blood flow during hemorrhage and hypercapnia in the rabbit. Am J Physiol 247:H40-H5

20. Busija DW 1986 Unilateral and bilateral sympathetic effects on cerebral blood flow during normocapnia. Am J Physiol 250:H498-H502

21. Lacombe P, Reynier-Rebuffel A, Mamo H, Seylaz. J 1977 Quantitative multiregional blood flow measurements during cervical sympathetic stimulation. Brain Res 129:129-140

22. Kennedy C, Sokoloff L 1957 An adaptation of the nitrous oxide method to the study of cerebral circulation in children: normal values for cerebral blood flow and cerebral metabolic rate in childood. J Clin Invest 36:1 130-1137

23. Bode $\mathrm{H}$, Wais U 1988 Age dependence of flow velocities in basal cerebral arteries. Arch Dis Chil 63:606-611

24. Horgan JG, Rumack CM, Hay T, Manco-Johnson ML, Merenstein GB, Esola C 1989 Absolute intracranial blood-flow velocities evaluated by duplex Doppler sonography in asymptomatic preterm and term neonates. AJR 152:1059-1064

25. Behrman RE, Lees MH 1971 Organ blood flows of the fetal newborn and adult monkey. A comparative study. Biol Neonate 18:330-340

26. Reivich M, Brann AW, Shapiro H, Rawson J, Sano N 1971 Reactivity of cerebral vessels to $\mathrm{CO}_{2}$ in the newborn rhesus monkey. Eur Neurol 6:132136

27. Rosenberg AA, Jones DJ, Traystman RJ, Simmons MA, Molteni RA 1982 Response of cerebral blood flow to changes in $\mathrm{PCO}_{2}$ in fetal, newborn, and adult sheep. Am J Physiol 242:H862-H866

28. Volpe JJ, Herscovitch P. Perlman JM. Raichle ME 1983 Positron emission tomography in the newborn: extensive impairment of regional cerebral blood flow with intraventricular hemorrhage and hemorrhagic intracerebral involvement. Pediatrics 72:589-601

29. Hernandez MJ, Brennan RW, Bowman GS 1980 Autoregulation of cerebral blood flow in the newborn dog. Brain Res 184:199-202

30. Younkin DP, Reivich M, Jaggi JL, Obrist WD, Delivoria-Papadopoulos M 1987 The effect of hematocrit and systolic blood pressure on cerebral blood flow in newborn infants. J Cereb Blood Flow Metab 7:295-299

31. Chemtob S, Beharry K, Rex J, Varma DR, Aranda JV 1990 Prostanoids determine the range of cerebral blood flow autoregulation of newborn piglets. Stroke 21:777-784
32. Paulson OB, Strandgaard S, Edvinsson L 1990 Cerebral autoregulation. Cerebrovasc Brain Metab Rev 2:161-192

33. Tuor UI, Edvinsson L. McCulloch J 1986 Catecholamines and the relationship between cerebral blood flow and glucose use. Am J Physiol 251:H824-H833

34. Johanson CE, Allen J, Withrow CD 1988 Regulation of $\mathrm{pH}$ and $\mathrm{HCO}_{3}$ in brain and CSF of the developing mammalian central nervous system. Brain Res 46:255-264

35. Craigie EH 1955 Vascular patterns of the developing nervous system, In: Waelsch H (ed) Biochemistry of the Developing Nervous System. Academic Press, New York, pp 29-50

36. Klein B, Kuschinsky W, Schrock H, Vetterlein F 1986 Interdependency of local capillary density, blood flow and metabolism in rat brains. Am J Physiol 251:H1330-H1340

37. Andrew DLE, Paterson JA 1989 Postnatal development of vascularity in the inferior colliculus on the young rat. Am J Anat 186:389-396

38. Bar T 1978 Morphometric evaluation of capillaries in different laminae of rat cerebral cortex by automatic image analysis: changes during development and aging. Adv Neurol 20:1-9

39. Bergstrom RM 1968 Development of EEG and unit electrical activity of the brain during ontogeny. In: Jilekand L, Trojan S (eds) Ontogenesis of the Brain: The Biochemical, Functional and Structural Development. Universita Karlova, Prague, pp 61-71

40. Yavin E, Harel S 1979 Muscarinic binding sites in the developing rabbit brain. Regional distribution and ontogenesis in the prenatal and early neonatal cerebellum. FEBS Lett 97:151-154

41. Gingras-Leatherman JL, McNamara MC, Hong JS, Lawson EE 1985 Development of methionine-enkephalin in microdissected areas of the rabbit brain. Brain Res 336:73-80

42. Vrennsen G, De Groot D, Nunes-Cardozo J 1977 Postnatal development of neurons and synapses in the visual and motor cortex of rabbits: a quantitative light and electron microscopic study. Brain Res Bull 2:405-416

43. Murphy EH, Magness R 1984 Development of rabbit visual cortex: a quantitative golgi analysis. Exp Brain Res 53:304-314

44. Hyvarinen J 1966 Analysis of spontaneous spike potential activity in developing rabbit diencephalon. Acta Physiol Scand 68(suppl 278):3-67

45. Harel S, Shapira Y, Hartzler J, Teng EL, Quiligan E, Van Der Meulen JP 1978 Neuromotor development in relation to birth weight in rabbits. Biol Neonate $33: 1-7$

46. Altman DI, Powers WJ, Perlman JM, Herscovitch P, Volpe SL, Volpe JJ 1988 Cerebral blood flow requirement for brain viability in newborn infants is lower than in adults. Ann Neurol 24:218-226 